Journal of

Health, Medicine and Nursing

(JHMN)

KNOWLEDGE OF NURSES ON SYNDROMIC MANAGEMENT OF SEXUALLY TRANSMITTED INFECTIONS IN PUBLIC FACILITIES

Maina Eva.Mumbi, Mwangi John Hiuhu, Njuguna Felix.Tharao and Maingi.Nyambura Nancy

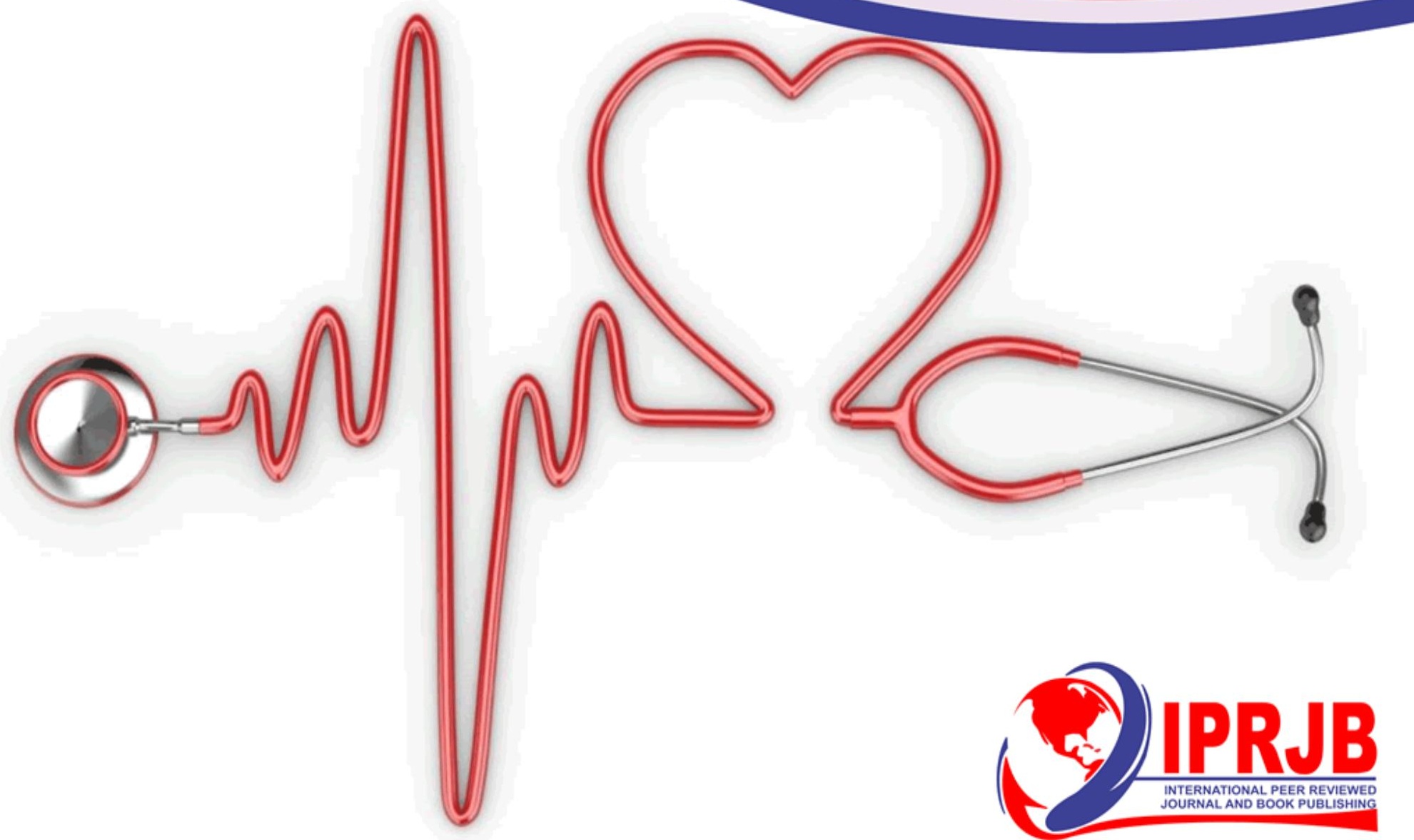


Journal of Health, Medicine and Nursing

ISSN 2520-4025 (Online)

Vol.5, Issue 5. No.1, pp 1- 12, 2020

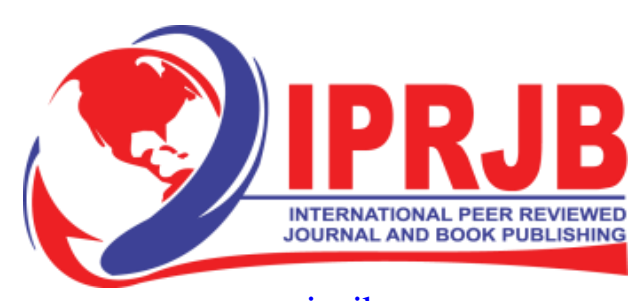

WWW.iprjb.org

\title{
KNOWLEDGE OF NURSES ON SYNDROMIC MANAGEMENT OF SEXUALLY TRANSMITTED INFECTIONS IN PUBLIC FACILITIES
}

\author{
${ }^{1}$ Maina Eva.Mumbi \\ School of Health Sciences: Kirinyaga University \\ Corresponding Author Email: evahmaina73@gmail.com \\ ${ }^{2}$ Mwangi John Hiuhu \\ School of Health Sciences Kirinyaga University \\ jheowho@gmail.com \\ ${ }^{3}$ Njuguna Felix. Tharao \\ Dedan Kimathi University of Technology, School of Nursing \\ ${ }^{4}$ Maingi.Nyambura Nancy, \\ Dedan Kimathi University of Technology, School of Nursing \\ nancy.maingi@dkut.ac.ke
}

\begin{abstract}
Purpose: The main purpose of this study is to assess the knowledge of nurses on syndromic management of STIs in public health facilities within Kirinyaga west Sub County.

Methodology: The study utilized descriptive cross-sectional study design, with a target population of 70 nurses working in 16 Kirinyaga west public health facilities. The dependent variable was applying syndromic approach management of sexually transmitted infections, independent variables as knowledge and practices. The study utilized purposive sampling technique to determine the sample size of 49 nurses. The study employed the use of a questionnaire as a data collection tool and check list. A pretest of the data collection tool was conducted at Karatina sub county hospital MCH/FP
\end{abstract}

Findings The study findings showed that $90 \%$ of the respondents had general knowledge of what syndromic approach is though $38 \%$ were not able to identify the common STIs syndromes and $39 \%$ couldn't correctly identify the STIs that present a genital ulcer. $45 \%$ depended on laboratory investigations to diagnose and manage STIs, while $74 \%$ had not undergone any training or CME in the last 2 years on syndromic management of STIs and 96\% reported that the health facilities they were stationed did not have readily available WHO/NASCOP 2015 guidelines. The respondents did not apply the syndromic approach in managing STIs and that, knowledge and practice on syndromic management of STIs among nurses in Kirinyaga west Sub County is low at $41 \%$.

Unique contribution to theory, practice and policy: There is need for more awareness through capacity building among health workers managing sexually transmitted infections in the communities and therefore the study recommends county Governments to organize for trainings and CMEs on STIs/syndromic approach and identify an STIs management focal person in public health facilities.

Keywords: Knowledge, Syndromic Management, STIs 
Journal of Health, Medicine and Nursing

ISSN 2520-4025 (Online)

Vol.5, Issue 5. No.1, pp 1- 12, 2020

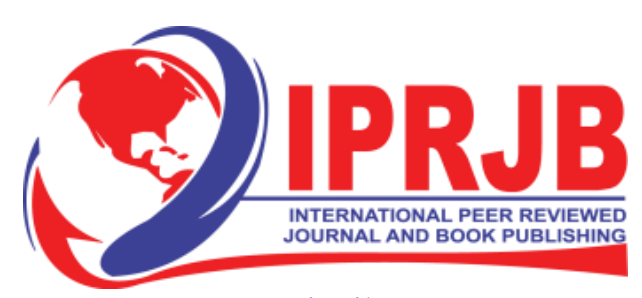

www.iprjb.org

\subsection{INTRODUCTION}

Sexually transmitted infections (STIs) include those infections, which are predominantly transmitted through sexual contact from an infected partner. Although the transmission of the infections is mostly due to sexual contact, other modes of transmission include placental, by blood transfusion, infected needles or by inoculation into the infant's mucosa when it passes through the birth canal. ${ }^{1}$

The syndromic approach is an answer to many of the obstacles to efficient STIs case management in developing countries. It is based on identifying a syndrome, a group of symptoms and easily recognized signs (what the clinician finds on examination) associated with a number of well-defined etiologies. Once a syndrome has been identified, treatment can be provided for majority of the organisms responsible for the syndrome. ${ }^{2}$ The presence of an untreated or mismanagement of an STI increases the risk of transmission of HIV during unprotected sex between an HIV infected and an HIV un-infected partner. STIs that cause genital ulcers (syphilis, HSV2 and chancroid) are most associated with increased risk of transmission. Despite the important role that STIs play in HIV epidemic, the focus on HIV has overshadowed the attention to STIs. ${ }^{3}$

STIs are among the world's most common infectious diseases, with an annual incidence exceeded only by diarrheal diseases, malaria and lower respiratory infections. Due to their high prevalence, particularly in developing country settings, STIs result in substantial productivity losses for individuals and communities, particularly where the majority of the population is less than 40 years of age. In developing country settings, STIs are among the leading causes of disability adjusted life years (DALYs) lost for women of reproductive age, exceeded only by maternal causes and HIV. ${ }^{4}$ As the most common of all infectious diseases, every day nearly 1 million people acquire a new STI, and more than 357 million new cases of curable STIs occur throughout the world each year, with sub-Saharan Africa estimates of 65million infections 25 per 100 adults annually ${ }^{5}$ Some of the complications of misdiagnosed and mismanaged STIs are; infertility, congenital abnormality, adverse neurological conditions, CVS risks, ectopic pregnancy and even premature death of neonates. ${ }^{7}$

According to the Kenya Service Provision Assessment report, in a health workers interview, $80 \%$ of health care workers reported having basic training on STI management. $50 \%$ of the interviewed providers reported that they had received training related to STIs management during the year before the survey. Only $25 \%$ reported applying the syndromic algorithm in their practice while managing STIs and $40 \%$ of the health care providers reported not always do they perform a physical exam on clients presenting with complains of an STI. This reflected that most of the health care workers, lacked sensitization on the revised versions of syndromic approach in management of STIs. ${ }^{8}$

One of the supportive elements for STI prevention and control is training. Training ensures that adequate STI management standards are met by all members of the health care team. ${ }^{9}$ Adequate training does not involve only biomedical aspects of STI diagnosis, treatment and prevention; it includes provider attitudes, beliefs and social stigma effects, confidentiality. ${ }^{10}$ Although basic training is ideally provided to every health Professional involved in any aspect of STI 
Journal of Health, Medicine and Nursing

ISSN 2520-4025 (Online)

Vol.5, Issue 5. No.1, pp 1- 12, 2020

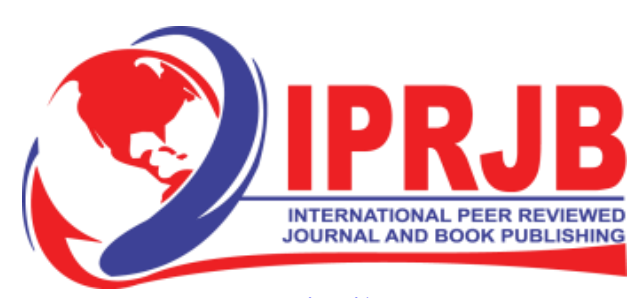

WWW.iprjb.org

\subsubsection{Respondents Nursing Qualifications}

This table represents the nursing qualifications of respondents.

Table 1: respondents nursing qualifications

\begin{tabular}{|c|c|c|c|c|}
\hline & $\begin{array}{l}\text { HIGHEST } \\
\text { QUALIFICATION }\end{array}$ & NUSRSING & FREQUENCY & PERCENTAGE \\
\hline 1 & Enrolled nurse & & 12 & $24 \%$ \\
\hline 2 & KRCHN/KRN/KRM & & 35 & $71 \%$ \\
\hline 3 & BSc Nursing & & 2 & $5 \%$ \\
\hline 4 & Any other & & 0 & $0 \%$ \\
\hline
\end{tabular}

It indicates that the highest nursing qualification is KRCHN/KRN/KRM $71 \%(n=35)$ followed by Enrolled nurse at 24\% ( $n=12)$, BSc Nursing qualification at 5\% $(n=2)$.

\subsubsection{Respondents Years of Experience Working As a Nurse}

This is a table representing respondent's years of working experience.

Table 2: respondents years of experience

\begin{tabular}{llll}
\hline & YEARS WORKED AS A NURSE & FREQUENCY & PERCENTAGE \\
\hline 1 & Less than one year & 0 & 0 \\
2 & $1-5$ years & 3 & 6 \\
3 & $6-10$ years & 10 & 21 \\
4 & $11-15$ years & 26 & 53 \\
5 & $16-20$ years & 6 & 12 \\
6 & Above 20 years & 4 & 8 \\
\hline
\end{tabular}

Table 2 shows that majority 53\% $(\mathrm{n}=26)$ of the respondents have served for $11-15$ years followed by, $21 \%(\mathrm{n}=10) 6-10$ years, $12 \%(\mathrm{n}=6) 16-20$ years, $8 \%(\mathrm{n}=4)$ above 20 years, $6 \%$ $(\mathrm{n}=3) 1-5$ years.

\subsubsection{Level of Health Facility of Respondents}

The pie chart below represents the level of health facility respondents are working.

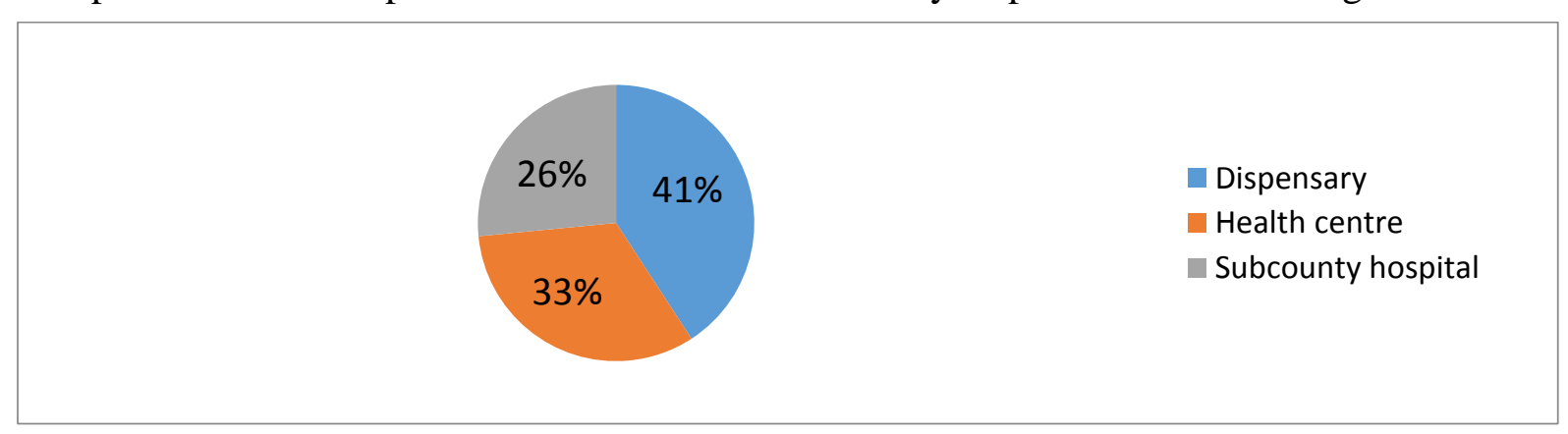

\section{Figure 3: Level of health facility of respondents}

Figure 3 indicates that majority $41 \%(n=20)$ worked in the dispensaries, $33 \%(n=16)$ worked in health centres and $26 \%(n=13)$ worked in the sub county hospital. 
Journal of Health, Medicine and Nursing

ISSN 2520-4025 (Online)

Vol.5, Issue 5. No.1, pp 1- 12, 2020

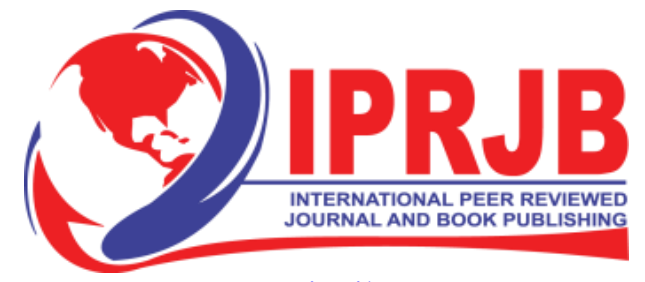

WWW.iprjb.org

\subsection{Nurses knowledge on syndromic management of sexually transmitted diseases}

This section presents data and analysis of respondent's knowledge on syndromic management of sexually transmitted diseases.

\subsubsection{Awareness of Syndromic Approach Management of STIs?}

This is a doughnut representing respondent's awareness of syndromic management of sexually transmitted infections.

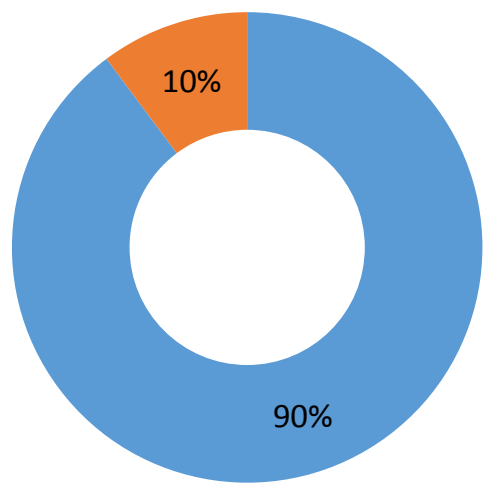

Figure 4.responses on whether nurses are aware of syndromic management of STIs

Figure 4 shows that $90 \%$ (44) are aware of syndromic approach management of STIs while $10 \%$ (5) are not.

\subsubsection{Respondents Knowledge on Common STI Syndromes}

This is a table showing respondents knowledge on common STI syndromes according to syndromic approach.

\section{Table 3 respondent's knowledge on common STI syndromes}

\begin{tabular}{lll}
\hline & Frequency & Percentage \\
\hline Urethral discharge in male & 4 & 8 \\
Vaginal discharge or pruritus & 5 & 10 \\
$\begin{array}{l}\text { Opthalmia neonatorum } \\
\text { Male and female genital ulcer } \\
\text { disease }\end{array}$ & 0 & 0 \\
Lower abdominal pain in & 0 & 0 \\
women & & 0 \\
All of the above & 30 & 62 \\
None of the above & 0 & 0 \\
I don't know & 10 & 20 \\
\hline
\end{tabular}


Journal of Health, Medicine and Nursing

ISSN 2520-4025 (Online)

Vol.5, Issue 5. No.1, pp 1- 12, 2020

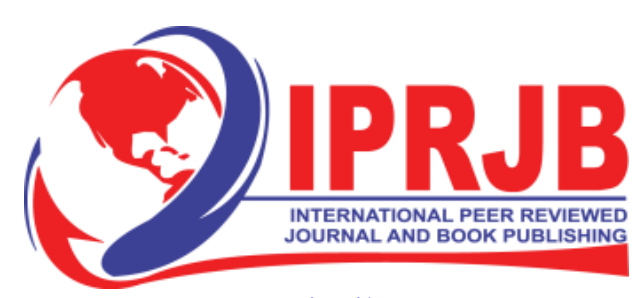

www.iprib.org

Table 3 shows that only $62 \%(n=30)$ of the respondents have knowledge of the common STI syndromes while $20(\mathrm{n}=10)$ did not know, $10 \%(\mathrm{n}=5)$ responded to vaginal discharge or pruritus and $8 \%(\mathrm{n}=4)$ responded to urethral discharge in male as common STI syndromes

\subsubsection{Respondents Knowledge on How They Diagnose and Manage STIs}

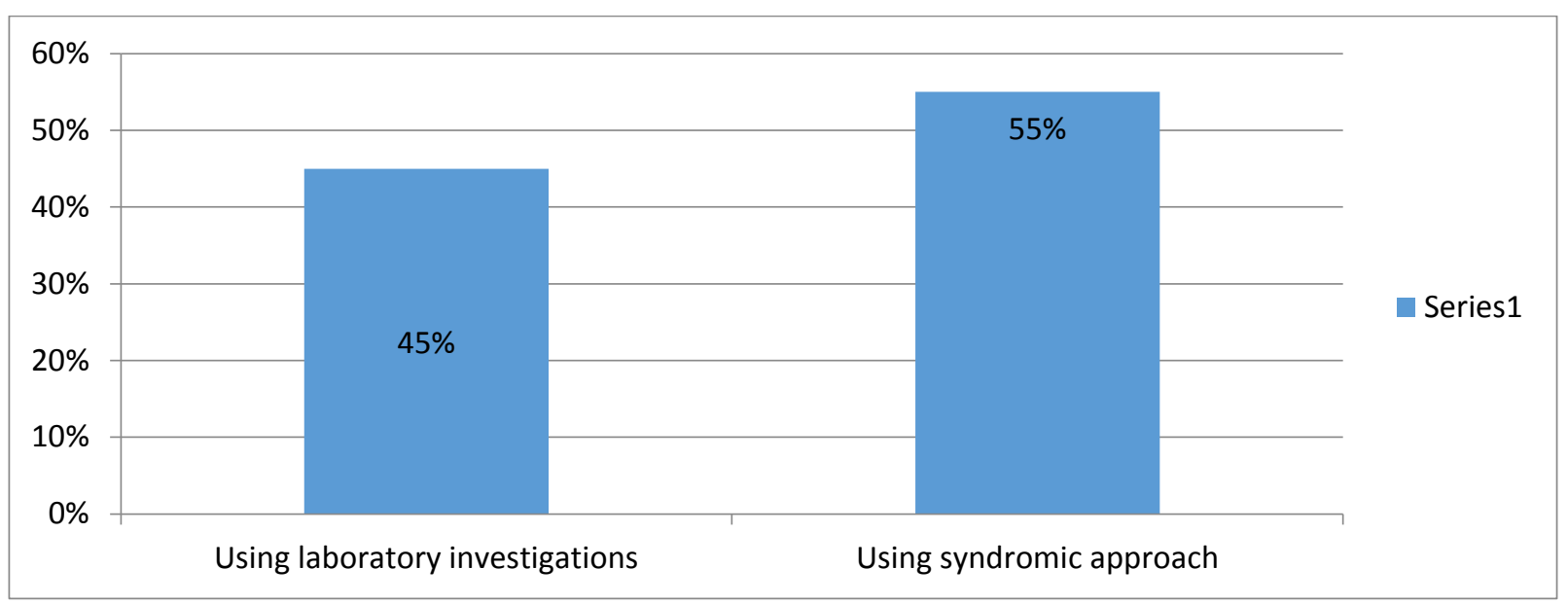

Figure 5 Response on knowledge of how they diagnose and manage STIs

Figure 5 indicates that $55 \%(n=27)$ of the respondents use syndromic approach, while $45 \%$ $(n=22)$ use laboratory investigations to diagnose and manage STIs.

\subsection{Respondents knowledge on the three STIs that present with Genital Ulcers}

Pie chart showing respondents knowledge on the STIs that present with genital ulcers.

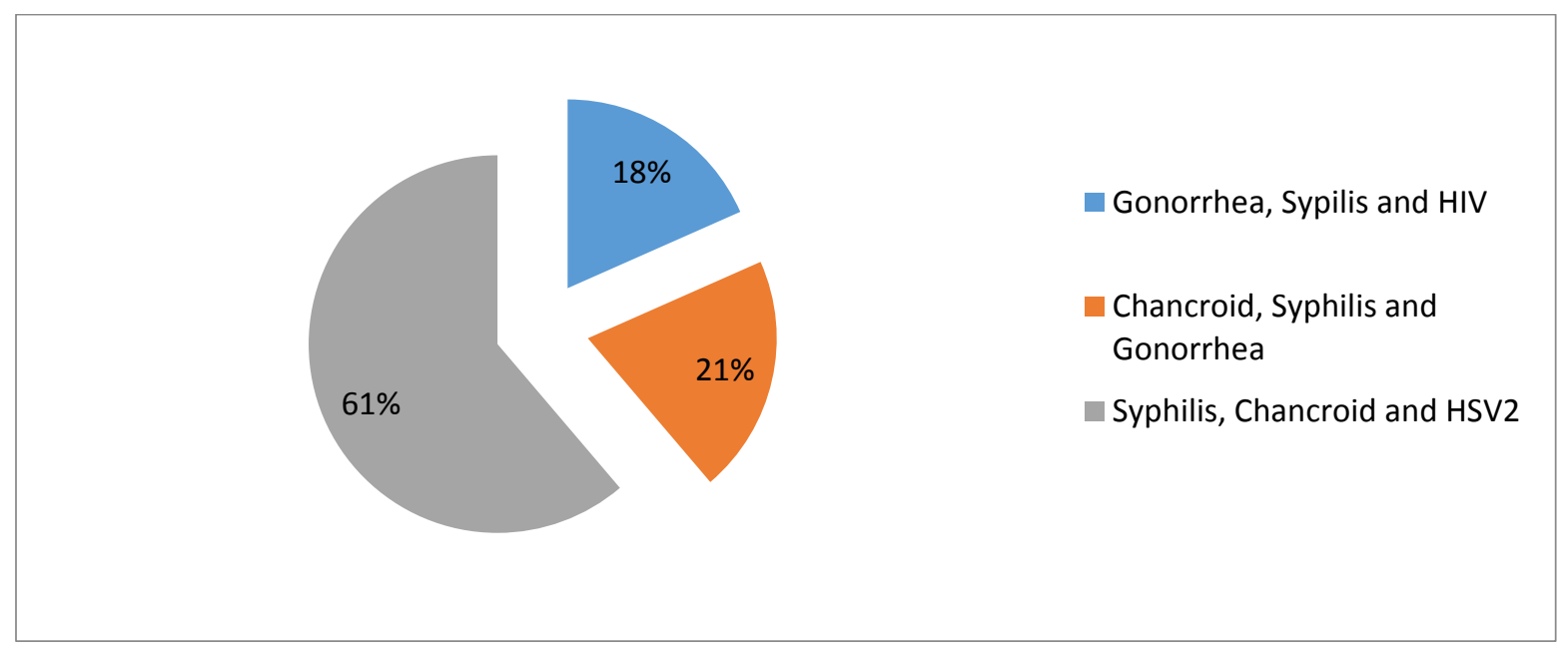

Figure 6 responses on knowledge of three STIs that present with Genital Ulcer

Figure 6 indicates that majority $61 \%(n=30)$ responded correctly to syphilis, chancroid and HSV2 as STIs presenting with genital ulcers. While $21 \%(\mathrm{n}=10)$ responded to chancroid, syphilis, gonorrhea and $18 \%(\mathrm{n}=9)$ responded to gonorrhea, syphilis, HIV as STIs presenting with genital ulcers. 
Journal of Health, Medicine and Nursing

ISSN 2520-4025 (Online)

Vol.5, Issue 5. No.1, pp 1- 12, 2020

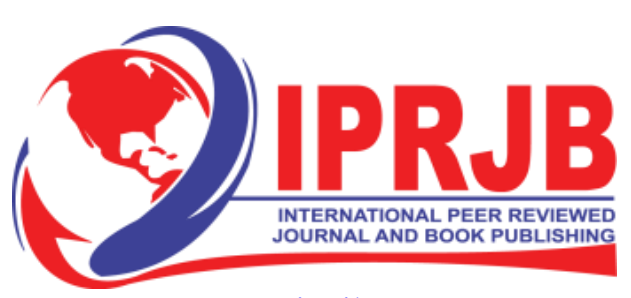

WWW.iprjb.org

4.3 Respondents Knowledge on Treatment of Choice for a Client with a Genital Ulcer That is Allergic to Penicillin

Table representing knowledge on treatment of choice for a client with a genital ulcer, that is allergic to penicillin.

Table 4: respondent's knowledge on treatment of choice for a client with a genital ulcer that allergic to penicillin

\begin{tabular}{lll}
\hline Treatment & Frequency & Percentage \% \\
\hline Benzathine penicillin & 0 & 0 \\
Doxycycline & 0 & 0 \\
Azithromycin & 42 & 86 \\
I don't know & 7 & 14 \\
\hline
\end{tabular}

Table 4 shows that majority of the respondents $86 \%(n=42)$ treatment of choice for a patient with a genital ulcer allergic to penicillin is Azithromycin while $14 \%(n=7)$ did not know the treat of choice.

4.3.1 Respondents Knowledge on Whether Laboratory Investigations are Required in Syndromic Management of STIs.

The following pie chart presents knowledge on whether laboratory investigations are required in syndromic approach.

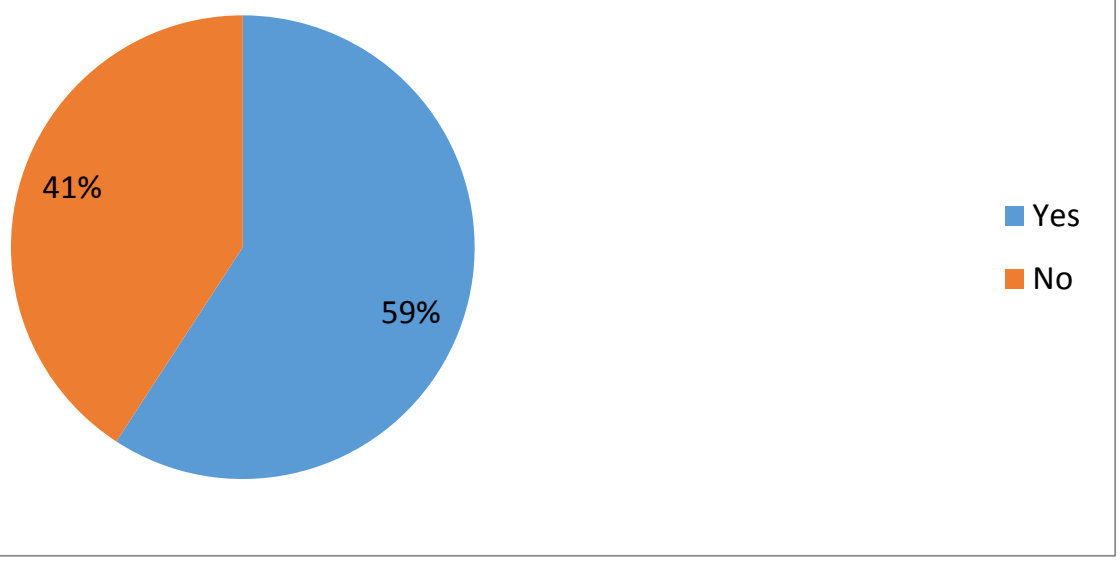

Figure 7 whether laboratory investigations is a requirement in syndromic approach management of STIs

Figure 7 indicates that $59 \% \quad(n=29)$ of the respondents are of the idea that laboratory investigations is a requirement in syndromic approach management of STIs, while $41 \%(\mathrm{n}=20)$ said that it is not a requirement.

4.3.2 Respondents Knowledge on at What Point are you Supposed to Consider Referring a Client For Investigations According to the Syndromic Approach Management of STIs.

The following table presents knowledge on when to consider referring a client for investigations according to the syndromic approach. 
Journal of Health, Medicine and Nursing

ISSN 2520-4025 (Online)

Vol.5, Issue 5. No.1, pp 1- 12, 2020

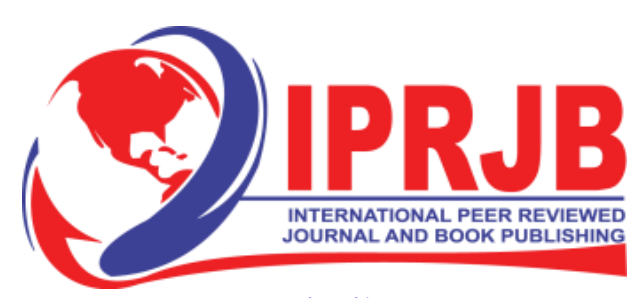

WWW.iprjb.org

Table 5 Response on knowledge of at what point you should consider referring a client for investigations

\begin{tabular}{lll}
\hline & Frequency & Percentage \% \\
\hline $\begin{array}{l}\text { If discharge persists after } 7 \\
\text { days of treatment of vaginal }\end{array}$ & 41 & 84 \\
discharge or pruritus & & \\
No need for referring & 5 & 10 \\
I don't know & 3 & 6 \\
\hline
\end{tabular}

Table 5 shows that $84 \%(n=41)$ of the respondents consider referring clients when there is persistent discharge after 7 days of treatment of vaginal discharge or pruritus. $10 \%(n=5)$ of the respondents see no need to refer patients for investigations at any point of the syndromic approach, $6 \%(n=3)$ of the respondents did not know.

\subsection{Respondents Undergoing a Training or CME within the Last Two Years on Syndromic Management of STIs.}

Graph presentation on percentage of respondents who have undergone training or CME on syndromic approach in the last two years.

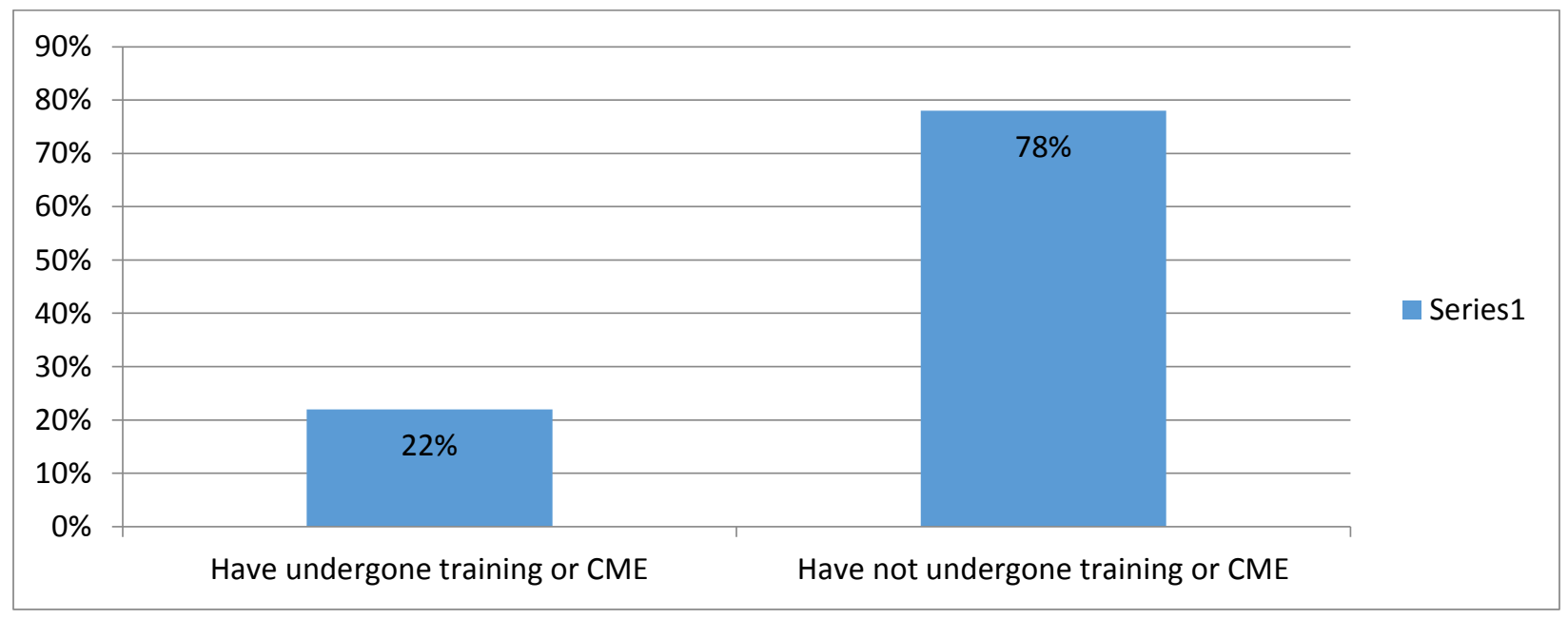

Figure 8: respondents undergoing a training or CME within the last two years on syndromic management of STIs.

Figure 8 indicates that $78 \%(n=38)$ of the respondents have not undergone any training or CME in the last two years on syndromic management of STIs. While $22 \%(n=11)$ of the respondents have undergone a training in the last two years, as part of the curriculum in nursing education upgrading programs which they had enrolled in. 
Journal of Health, Medicine and Nursing

ISSN 2520-4025 (Online)

Vol.5, Issue 5. No.1, pp 1- 12, 2020

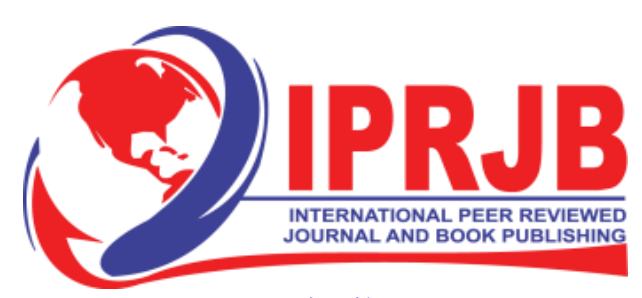

WWw.iprib.org

\subsubsection{Respondents Knowledge on the 4cs of Good STI Management}

The table below presents respondents knowledge on the 4Cs of syndromic approach.

Table 6 respondent's knowledge on the 4Cs of good STI management.

\begin{tabular}{lll}
\hline 4Cs & Frequency & Percentage \\
\hline $\begin{array}{l}\text { Compliance, consistency, } \\
\text { conformity and counseling }\end{array}$ & 4 \\
$\begin{array}{l}\text { Counseling, compliance, } \\
\text { condoms and contact }\end{array}$ & 86 \\
$\begin{array}{l}\text { treatment } \\
\text { Counseling, condoms, }\end{array}$ & \\
consistency and conformity & 10 \\
\hline
\end{tabular}

Table 6 most of the respondents $86 \%(n=42)$ have knowledge of the 4Cs of STI management, while a few $10 \%(n=5)$ and $4 \%(n=2)$ could not respond to the 4 Cs of STI management.

\section{Discussion}

Majority of the respondents $71 \%$ were females, remaining $29 \%$ were male, most of them $32 \%$ were between 36 to 40 years having a small number above 46 years. Seventy one percent of the respondents are registered nurses having basic training in STIs management, 53\% had 11 to 15 years of working experience while $8 \%$ had 20 years and only $6 \%$ had 1 to 5 years of work experience this shows most of the respondents have experience in managements of patients presenting with various conditions. Most nurses $41 \%$ were stationed in dispensaries; all respondents offered STIs management integrated with other services. This partly agrees with study findings that, almost all facilities (94\%) offer STI services as a primary service, usually in the general outpatient, as well as in the family planning services area and the ANC service area. STI services are available five days per week in $95 \%$ of facilities that offer the service. About two-thirds of facilities offering STI services have STI services integrated into FP services. ${ }^{7}$ It also relates with a study finding that, more than half of facilities offer STI services in ANC, FP, and general outpatient areas which are mostly serviced by Nurses. ${ }^{11}$

Almost all $90 \%$ of the respondents have general knowledge on syndromic approach management of STIs, only $10 \%$ had no idea what it is. $62 \%$ of the respondents had knowledge on the common STI syndromes; urethral discharge in male, vaginal discharge or pruritus, opthalmia neonatorum, male/female genital ulcer and lower abdominal pains in women. It agrees with a study that, although basic training is ideally provided to every health Professional involved in any aspect of STI management as a foundation, with the current revised STI management tools (syndromic approach) there is need for refresher training or continuing education based on program monitoring and evaluation. ${ }^{11}$

Forty five percent of the respondents depend on laboratory investigations to diagnose and manage STIs which indicates that they do not follow the syndromic approach algorithm which largely focuses on symptomatic presentation. This delays treatment of those presenting with symptoms of an STI, which is against a WHO report stating that, STI control in low and middle income countries has been shaped by clinical case management guidelines promoting syndromic management. This approach uses algorithms based on groups of genital symptoms to guide STI treatment for people seeking care, without the use of laboratory tests. Syndromic management is 
Journal of Health, Medicine and Nursing

ISSN 2520-4025 (Online)

Vol.5, Issue 5. No.1, pp 1- 12, 2020

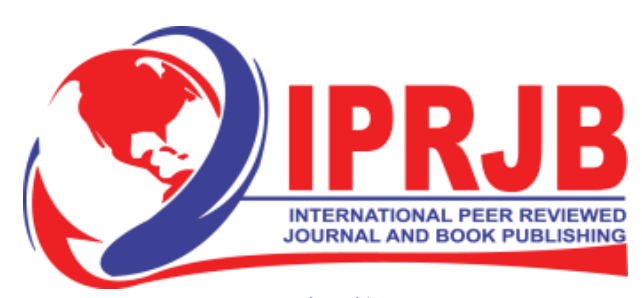

WWW.iprib.org

simple, assures rapid, same day treatment, and avoids the expensive diagnostic tests that are often unavailable in resource limited settings; it's cost effective. ${ }^{11}$

Thirty nine percent of the respondents could not correctly identify the STIs that present with a genital ulcer which are syphilis, chancroid and HSV2. More than half of the respondents 59\% mentioned that a laboratory investigation is a requirement in syndromic approach contradicting focus on syndromes and symptomatic presentation. while $84 \%$ of the respondents correctly mentioned at what point it should be considered to refer a client for investigations .This is in agreement with a study by carried out in rural Vietnam that, suboptimal knowledge and reported practice found among healthcare providers in rural Vietnam imply the urgent need of interventions to improve STI knowledge and practice for providers at grassroots healthcare level. $^{12}$

Majority of the respondents $74 \%$ have not undergone training or continuous medical education in the last two years on syndromic management of STIs which is indicative that majority of nurses are not updated on the 2015 WHO/NASCOP guidelines on syndromic approach . Which is in agreement with a 2015 study in Gofa Zone, south Ethiopia on knowledge of clinicians on syndromic management of STIs was $27.2 \%$, only $8.3 \%$ follow the national guideline and few were trained on syndromic management of STIs. The general compliance with the recommended national guidelines of STI management is poor, hence recommended need for refresher training or continuing education based on program monitoring and evaluation.

Though majority of the respondents $86 \%$ were able to identify and mention the 4Cs of STIs management supporting a CDC 2013 study finding that, basic training is ideally provided to every health Professional involved in any aspect of STI management as a foundation.

\section{Conclusion}

Majority at of the respondents $90 \%$ had general knowledge of what is syndromic approach management of STIs, though some of them $39 \%$ were not able to identify the common STIs syndromes and STIs that present with a genital ulcer which is an important aspect in timely identification and management of STIs.

Most of the respondents $45 \%$ did not follow the syndromic algorithm by depending on laboratory investigations to diagnose STIs hence delaying treatment; this is a contributing factor to the complications related to STIs.

\section{Recommendation}

Based on the study;-There is need for trainings and CMEs on STIs/syndromic approach and identifying STIs management focal persons in the 16 public health facilities. The identified focal person through OJTs and health facility CMEs to encourage and strengthen nurses skills in practice of managing STIs. There is need for provision of syndromic approach guidelines to be available in all the public health facilities and the updated 2015 syndromic algorithm (flow chart) is displayed in all service delivery points.

\section{REFERENCES}

1. DC DUTTA'S, (2013). Text book of Gynecology Jaypee. Brothers' medical publishers Ltd, New Delhi.146 - 159. 
